\title{
Facing uncertainty in education: Beyond the harmonies of Eurovision education
}

European Educational Research Journal 2016, Vol. 15(6) 619-627

(c) The Author(s) 2016 Reprints and permissions: sagepub.co.uk/journalsPermissions.nav DOI: |0.1|77/|474904||666973 | eerj.sagepub.com

\section{Sharon Todd}

Maynooth University, Ireland

\begin{abstract}
One of the most pressing concerns identified in current European educational discourse is about the transitions of students from school to higher education and from educational institutions to the labour market. Government anxieties over the precariousness of the future has led to increasing regulation and measurement of 'skills' and 'competences' for students in an attempt to suture over these transitions. However, in doing so, policies risk further alienating and dehumanizing students in turning classrooms into testing zones and places of high risk assessment that pigeonhole students into limited futures. I argue in this paper that if youth are to contribute meaningfully to a future that is, by definition, not something that is certain or knowable in advance, a more appropriate response will be to think about the kinds of sensibility that would help students orient themselves toward a changing and unpredictable world. This paper outlines how a project of facing uncertainty (what the poet John Keats referred to as 'negative capability') actually shifts the terms upon which policies and curricular reform can be constructed.
\end{abstract}

\section{Keywords}

Buddhism, European policy, negative capability, skills and competences, transition

Let me begin by giving a sense of the overall position this paper develops. European anxieties about the precariousness of the future have led to increasing regulation and measurement of the 'skills' and 'competences' of students, in an attempt to suture over transitions from school to higher education and from educational institutions to the labour market. What this focus on transition seems to be concerned with is how education can help make things go as smoothly as possible so that integration with what one is transitioning toward is achieved. But no matter how well-intentioned and necessary such integration might be, the framing of the relationship between education and transition worries 
me because, in my view, it leaves little room for thinking about education itself as a process of transition, which implies ongoing change and transience.

As I argue here, education is not only about 'servicing' various kinds of transition, but is also itself a transitional practice; and, more to the point, I will be suggesting that if we think of education in terms of change and its processes (and not merely about making change less painful), then our capacity for dealing with uncertainty (about the future, the economy, the social and political arenas, as well as about ourselves) actually invites a different kind of relation to the kinds of research we do and the educational policies we hope to influence. It actually gets at the heart of what I am calling the 'existential condition' of education.

In what follows, I focus first on examining critically the European context of transition, what I term 'Eurovision education', looking in particular at the Education and Training 2020 guidelines. ${ }^{1}$ Here, I outline what I see is problematic about how transition has been identified and the relationship it has to education. The paper then explores the conceptual shifts that need to take place in order to address these problems, and in order to offer a different relationship between the idea of transition and the practice of education; such shifts are deemed necessary in order to sing a different tune. This is followed by a more fulsome discussion of the notion of 'transition' and what it means for the existential conditions of education - conditions that focus on youth's experiences as opposed to their behaviours. Taking up these conditions seriously, I draw on Buddhist philosophy as a way of framing uncertainty and change as part of the existential landscape of education. To this end, I wish to move away from the harmonious vision that 'Eurovision education' seeks to promote. Finally, I work through the idea of facing uncertainty as a research and policy task in the field of education, and how I think we, as educational researchers, need to champion alternative voices; that is, those who become marginalised in and through enforced harmony.

\section{Singing the right song, or Eurovision for European education}

A major part of the feature of European education policy over the past few decades is the push toward commonality underlying policies concerned with education and transition. Guy Neave, in 2003, made an astute comment about this relationship in the Higher Education sector:

It could be argued, with no little weight, that the past two decades for Europe as a whole have been a saga of a vast and never-ending transition - to a market economy, to strategic management, to new managerialism, towards the Evaluative State, towards agency control; a veritable procession, a decade or more long, singing songs of expectation, accountability and diversification, variously applied to such areas as funding, students and types of establishment now gathered under the general rubric of 'higher education'. (Neave, 2003: 135)

Neave's comments have proven to be apt not only, in my view, for higher education, but also for the field of education more broadly. The songs of which he writes might not seem too dated (at least just yet), even though the lyrics were written before the numerous economic collapses we have witnessed since 2008, the increased influence of the OECD and PISA on government regulation of educational systems, and even before the phrase 'circular economy' was in currency. But what he points to is the difficulty for - or inability of - governments to sing out of tune, or to opt out of the choir altogether. In the harmonisation of European educational policy with regard to transition, governments are expected to comply with - and indeed are involved in the construction of - a whole set of assumptions that view what counts as education in a very particular manner.

In a Joint Report of the European Council and Commission released on 26 August 2015, the EU outlined its concerns with transition for youth from 'education' to 'work' and its objectives for Education and Training 2020. I want to spend a little time mapping out what is at stake in the Joint Report in order to uncover some key assumptions about what kind of Eurovision for education is being claimed. 
The Joint Report discusses the significance of identifying priorities that will 'anticipate and meet the rapidly changing needs of labour markets'; and that will support 'the transition to a circular economy' (European Commission, 2015: 2). Moreover, the report states that such priorities are seen within a context where 'inequality is at its highest level in 30 years'. To respond to these large and expansive economic conditions it is recommended that the focus needs to be on are six priorities for education, which largely emphasise the development of skills and competences across a number of areas. I have listed these priorities here, with a more detailed focus on the skills and competences described in parentheses for selected priorities.

1. Relevant and high quality skills and competences, focusing on learning outcomes, for employability, innovation and active citizenship.

(These include: transversal skills; key competences; re-igniting life-long learning strategies promoting transition between schools, VET, HE and work.)

2. Inclusive education, social cohesion, equality, non/discrimination and promotion of civic competence.

(These include: tackling discrimination and gender gaps; promoting civic, intercultural, social and relational competences.)

3. Open and innovative education and training, including fully embracing the digital era.

4. Strong support for educators.

5. Transparency and recognition of skills and qualifications to facilitate learning and labour mobility.

(These include: fostering transparency, quality assurance, validation of skills and qualifications; simplifying and rationalising the transparency; $\mathrm{HE}$ internationalisation and mobility.)

6. Sustainable investment, performance and efficiency of education and training systems. (These include: attracting private actors and capital into education; evidence-based policy making; performance-based funding and cost-sharing.)

In particular, areas 1, 2, and 6 congregate around skills and competences and their measurability through performance indicators, and are of direct relevance to how the EU positions education in relation to transition.

What is clear from the report is that the language of education is a language that has been hijacked by assumptions about efficiency, behaviour and management. Not only has 'education' as a term been reduced to 'learning' as Biesta (2010) claims, but learning itself has also been given a narrow bandwidth, becoming that which we can 'see' and 'measure' through 'outcomes', 'outputs' and 'performance'. But what is new here? This is an old tune, played for the better part of almost 30 years. The neoliberal critiques written in the 1990s pointed to similar constellations of terms and vocabularies. What is perhaps relatively new is not so much what it says, but how what it says does two things:

1. The EU, through its policies, has become a uniform voice for education on this continent, leaving very little room for alternative voices (both national and community-based) to be heard; and

2. This Eurovision education is concerned with controlling social uncertainties; it actually assumes that education can assuage the problems of the economy, the social field, and political participation through the learning of certain skills and competences.

Not only does this, as Hannah Arendt (1983/1968) claimed, place the burden of fixing the world inappropriately on the youth who have had no hand in creating its problems, but it also suggests, in my view, an inability to tolerate uncertainty itself. This inability then leads to a false, delusional 
sense of education as being able to stabilise uncertainty. Under this logic it is no wonder that education becomes merely an instrument to serve social and economic ends. However, what I will be suggesting instead is that a shift to seeing education itself as a process fundamentally engaged with uncertainty actually makes it more - not less - valuable than seeing it as a vehicle for skills management and training.

\section{What's wrong with rewriting the Eurovision song?}

So, if we look at the problem as I see it crystallised in this Joint Report, what is driving current policy is a desire to stabilise social uncertainty by instrumentalising education as a practice through which one comes to learn certain skills and competencies which can then be transferred onto the social field. Education becomes the handmaiden, or back-up vocals, for policy agendas framed by social and economic problems. Education, it appears, does not exist on its own terms but, rather, only in relation to the social (economic) conditions it is supposed to ameliorate. Policies try to smooth over uncertainties of social and economic life by fixating on a response that can only ever be inadequate for addressing the problem, because the problem is not purely an educational one to begin with. If education is supposed to be able to fix problems, why hasn't it done so already? Is it really because we have failed to 'implement' policy properly, or is there something about the way we are viewing education itself that is the problem?

I do not deny the overwhelming challenges facing youth today and do not wish to minimise them. Together with being confronted by the highest levels of inequality in 30 years, European states are increasingly facing difficulties in providing the conditions for youth to live meaningful lives, where housing, relationships, employment and schooling are not factors of alienation but become, rather, possibilities for contributing to one's own and others' flourishing. OECD statistics for Ireland reveal extraordinarily high numbers of youth who are in neither employment nor education: in Spain those figures are double (OECD, 2013). These are severe social and economic problems which demand appropriate social and economic responses. While education has a clear role to play, as I argue below, it is not the role defined by the instrumental assumptions of Eurovision education. Instead, to my mind, such a role must be rooted in defence of education as something other than 'learning', 'skilling' and 'training'.

A response that is educational cannot be concerned primarily with skills and competences. The first shift that needs to take place is towards thinking how problems of transition can be rearticulated as educational questions, and not simply assume that education is the answer to a problem already defined elsewhere (by capitalist concerns, for example). That is, the educational field (teachers, researchers, students) needs to claim boldly what the issues are on its own terms. According to this view, perhaps 'transition' is not the problem at all but, rather, that the problem is estrangement, disaffection and alienation, caused by over-regulation, excessive testing and pressures to become something or someone at the end of the day based on someone else's deluded sense of stability of what the future holds: I am thinking here of teachers as much as youth. The language we use to articulate what is important in education needs to be rooted in 'education', not in economics or any other sphere; we are otherwise posing somebody else's questions, singing someone else's song. To me, if we are going to take youth disaffection seriously, we need to confront the uncertainties youth are facing not by skilling them up and telling them 'now you're ready to face the world we have imagined for you', but by engaging that uncertainty honestly, directly and with humility - that is, by rethinking uncertainty from an educational vantage point; and this brings me to my second shift.

This requires putting in place policies that respond to the human element in education. In order to construct both viable and meaningful education, we cannot be focused primarily on behaviours 
(their measurement, their usefulness, their standardisation); rather, we need to focus on experience (the quality, the meaningfulness, the unpredictability). This means viewing skills and competences (since these terms probably won't go away entirely) from the perspective of this existential condition and not from the perspective of their purported 'usefulness' to a system that has been defined by other, extrinsic to education, interests.

What transforms people's lives are not simply the skills or competences they 'obtain' in an acquisition model of education, as a series of behaviours that can then be transferred into appropriate jobs, civic responsibilities, and the like. Skills and competences are only the metaphorical tip of the iceberg in education. Rather, what transforms people's lives are the unpredictable experiences of becoming. I don't know how many personal narratives I have come across in which youth and adult students (and I include myself here) claim that education is what changed them, what made a difference to how they live their lives. In this they (and I) are not talking about learning a particular skill (although this can be part of it), but about being engaged in a project that has meaning, that causes one to shift perspective, to see things familiar in unfamiliar ways, to paraphrase Maxine Greene (1988). Education, according to this view, is an existential experience that is not something to be controlled but which is open to surprise and uncertainty. While the knee-jerk reaction in facing grave social and economic problems is to suture over the uncertainties they bring through education, what I am suggesting is that it would be better to accept uncertainty as a valuable feature of education itself and think about how that might actually inform educational policy from the bottom of the (metaphorical) iceberg up. In other words, a response to uncertainty is to face uncertainty meaningfully, not to pacify it through a Eurovision lullaby.

\section{The beginnings of a different tune}

To sum up thus far, I have argued for a different relationship between education and transition different from the instrumental one that currently characterises it; one that actually faces social and economic uncertainties by allowing the existential uncertainties of the educational process itself to inform how it is we ought to face them. Before proceeding to flesh this out more thoroughly, I want to explore briefly how transition as a term actually functions to support this view and should not be seen as merely something that belongs to Eurovision education's song lyrics.

Transition always implies the existence of a state from which one is transitioning and of a state to which one is transitioning. From its Latin root, it denotes a 'going across or over'. ${ }^{2}$ What one is transitioning from is a state located in a 'past' that is open to interpretation (youth disaffection with education systems, unemployment, etc.); what one is transitioning to can only ever be speculation and projection of a 'future' which is, by definition, not entirely certain. However, it seems to me that if we are going to think about education beyond past tyrannies and future delusions, we need to think of the present as the proper time of education. The time of the present, as Hannah Arendt (1983/1968) claims, is located in the gap between the two, between past and future. Masschelein (2011), in seeking to identify the time of education in the present, focuses specifically on Arendt's depiction of this 'gap', which is not the 'present as we usually understand it' (Masschelein 2011: 11), but is a disruption in the supposedly continuous flow of time; and what disrupts the present is the assertion of one's own existence - that is, I 'am', I 'exist' in the present. On Masschelein's reading of Arendt, it is the co-temporality of existence and the present that ought to lie at the heart of our educational endeavours - indeed, this is what Masschelein calls the 'educational present': a time in which we become present.

Although Masschelein asks us to suspend our interpretations of the world in order to experience the present, the 'educational present', that space where we 'exist', is, for me, also a space inhabited by others of flesh and blood who are also making life in the 'present'. Such a life is interconnected, 
interdependent and relational (Todd, 2011). The 'gap' between past and future that is the 'educational present' is, for Arendt, something neither abstract nor general but occurs as a specificity where speech and action occur, where existence can flourish as an interruption of our interpretations of the past and the illusory projections of the future. We become 'present' not as a 'moment' of continuous time, but as a disruption to the expectations that are laid out for us and by us; and we do so in the world with others, even if our achievements seem to belong to a solitary self. To state it in the terms of the topic of this paper, the 'educational present' is about a life 'in transition': not a transition from or a transition to, but a state of suspension from the tyrannies of dominant ideologies about what we are and what we should be. Transition is about 'who' we are as relational subjects, etching out a life of meaning with others in complex and changing circumstances. Transition is thus not a one-off event: it is a continual process of change in which one's existence is always involved in relation to that of others. Education, therefore, is about creating conditions that support such transitions, that enable students to develop an orientation to life which cannot be reduced merely to the learning of individual skills and competences, but is instead focused on an approach to uncertainty, and is life-affirming and sustainable.

\section{A song of change and uncertainty}

What is interesting about the word 'transition' is that it also shares its Latin roots with the word 'transient' as that which 'passes over' and is a 'passing without continuity'. Transition and transience share, therefore, a sense of 'arising and passing away' that is familiar to Eastern thought, particularly the Buddhist tradition. A life 'in transition', as noted above, is one caught in suspension between the disappearance of the past and the arrival of something new. While the ancient Greek philosopher Heraclitus, who lived at the same time as the Buddha, understood the universe as being in continuous flux, what is worth drawing from the Buddhist tradition more specifically is the idea not only of change - that things are never the same or stable - but also of a constant appearance and disappearance - that things come and go, they emerge only to vanish again. Indeed, from a Buddhist perspective, this is the only certainty we can possibly have. In terms of our theme of transition this implies an ongoing state of uncertainty in education, not simply one that exists momentarily between secondary and tertiary education or between tertiary education and the workforce. Moreover, Buddhist philosophy offers a way of orienting ourselves to this uncertain world of transience which is never-ending by encouraging one to be in the 'present'.

Thus, in this section, I want to map out two primary aspects of uncertainty in relation to this Buddhist understanding. The first is concerned with seeing education as about developing a sensibility to the world that both recognizes 'transience' as a central feature of experience and allows for meaningful existence to emerge in the present (as I discussed above). The intention here is to make our orientation to 'transience' a core element of the 'transitional', existential condition of education. The second aspect is concerned with seeing this orientation to transience as the aesthetic work of education, and here I will be introducing the phrase 'negative capability' as coined by the poet John Keats (Colvin, 1925) as a way of framing this discussion.

First, within the Buddhist philosophical framework transience is one of the cornerstones of existence. In place of seeing the vagaries of life as elements to control or overcome, Buddhism suggests instead practising acceptance of life's uncertainties. Such acceptance means confronting the difficulties such uncertainties bring, as well as the beauty to be found in knowing how transient life is. We, in the proverbial West, might be inclined to think of such an attitude of acceptance as a problematic acquiescence or complacency to the world we live in, rife as it is with poverty, unemployment, and the problems of 'transition'. But, in the Buddhist sense, accepting uncertainty does not have anything to do with agreement. Rather, it is the condition for agency - it allows us to make 
judgements of agreement and/or disagreement. The idea is that if we can accept (or truly see) what is, then we are in a much better position to respond.

It is because things are transient that we are called to action; our lives are not lived in the imagined future, but in the present with others. This focus on the transient nature of things means having to relinquish my certainty, but not to relinquish my responsibility. This is primarily because, for Buddhism, I am deeply connected to the world around me and live a relational existence; that is, the Buddhist position - and I suggest it is one worth pursuing in order to reframe education beyond an instrumentalist model - is that of seeing education as concerned with an openness to uncertainty that is responsive to others (both human and other than human) with whom we share the world. The Buddhist scholar, Stephen Batchelor, writing about meditation, says something about this that in my view speaks directly to education:

...meditation is not about gaining proficiency in technical procedures...[but is] the ongoing cultivation of a sensibility, a way of attending to every aspect of experience within a framework of ethical values. (Batchelor, 2014: 38)

One could almost substitute 'meditation' with 'education' here; that education is not merely about technical proficiency (skills and competences), but is something much broader, involving attending to experience in ways that are framed by a concern for others with whom we share the world. Such attending is an approach or orientation to the world from which, I argue here, we need to build our educational policies, because it is in this, and not particular skills or competences, that the transformational potential of education lies.

As for my second point, when we consider what creating such an orientation to the world entails, it is clear we are not talking about mere cognitive acquisition but, rather, a way of attending to experience that is closer to what we consider to belong to an aesthetic sensibility. As I have discussed in detail elsewhere (Todd, 2015), and introduced above, such sensibility was aptly rendered by the English poet, John Keats, as 'negative capability': negative capability 'is when man is capable of being in uncertainties, Mysteries, doubts, without any irritable [impatient] reaching after fact \& reason...' (Colvin, 1925). On this account, there exists an open orientation to life that is not to be closed down by our too quick search for definite answers and explanations; instead, negative capability is about creating opportunities for 'accepting' uncertainty (and the mystery this entails) without seeking to encapsulate it within categories of understanding (that is, without rushing to fact or reason). Furthermore, negative capability, as a capability, signals that such an orientation is about an adeptness, a way of being that can be encouraged and possibly cultivated. There is thus a deeply 'aesthetic' dimension to this orientation to life and the world that does not map easily onto the conventional ordering of skills and competences so often presented in Eurovision educational contexts as discussed above. That is, the aesthetic dimension of education is not to be confused with acquiring certain behaviours since it has to do with the existential experiences of our encounters with the world. This is, indeed, what Batchelor (2014) calls the 'everyday sublime'. It is the experience of confronting the excesses of the world, which cannot be adequately captured in concepts, images, or words. As Batchelor says, 'They overreach us, spilling beyond the boundaries of thought' (Batchelor, 2014: 37). When we seek to order education into systems of performance and testing, the risk is that our experiences are seen not to have any value and they are not thought to be important. This, in my view, exacerbates the alienation and disaffection of youth from schools, civil society and the workplace, because it does not tap into what it is meaningful about life itself. As Batchelor noted, 'for the human animal who delights and revels in her place, who craves security, certainty and consolation, the sublime is banished and forgotten. As a result, life is rendered opaque and flat' (Batchelor, 2014: 37). Thus the attempt to place primary emphasis on skills' 
acquisition in order to make the world more 'certain' is actually in danger of turning education into a lifeless enterprise where youth become even further alienated from their own lives. Moreover, Eurovision education misses an opportunity to make education genuinely responsive to social and economic uncertainties, because it prevents youth from developing their openness to uncertainty - which is what education is all about.

As mentioned earlier, what makes education truly transformative (and we need to understand this if education is to have lasting effects) is not the type of skills or competences that are learned, but the qualities of experience that 'being educated' enables. In this sense, an education in negative capability, what could perhaps be called an 'aesthetic education in the everyday sublime', can provide us with a different register, a different key signature, if you like, in which to compose an alternative to Eurovision's tired refrains.

\section{Finale - singing a different tune}

Where to go from here? How can research and policy be informed by an approach to education that takes experience, and more specifically an orientation to experience, as the sine qua non of education's most fundamental task? As discussed above, Eurovision education seems to have bracketed out the human element of education and, in so doing, only conceives of education as an 'instrument' that services the larger social and economic systems of which it is a part. But what I have been arguing is that education is neither an 'instrument' nor a subservient 'part' of the system, but rather a process of transition and change, and is necessarily engaged with the uncertainties of life. This transformational dimension of education places it in a unique position to respond meaningfully to the experiences of uncertainty that youth encounter. For this reason, seeing education primarily in terms of skills and competences deadens its potential, flattening it out into a monotonous tune of performance, measurement and testing. In order to further its transformational potential, I have argued instead for developing an aesthetic approach where it is education's capacity to promote an orientation of openness to uncertainty, what I term 'facing uncertainty', that offers a way of reframing our approaches to policy and research.

Both research and policy concerned with transition need to focus more directly on addressing specifically educational questions - and resist tendencies to instrumentalise education. As we have seen from the Joint Report (European Commission, 2015), while there is much discussion on what education can 'do' for the economy and society, no consideration is given to what is particularly human about educational contexts. That is, it does not build on what education already 'does' - the practices that transform human lives in ways that make life more meaningful for many, both teachers and students. This is the experiential base rooted in practice upon which to build curricular reform and assessment practices.

Research cannot be complacent here if it is to contribute to changing the face of how we live through - and optimally transform - current Eurovision policy. This seems a daunting task, and I am not naïve about how the ET2020 strategies feed into strategic research priorities of Horizon 2020, ${ }^{3}$ and how national funding agencies, in an attempt to get their share of pot, are streamlining their own research agendas to fit more comfortably with these transnational goals. Nonetheless, it behoves us as researchers to respond to the flatness of Eurovision education by becoming more jazz-like, perhaps a little more improvisational, in composing dissonant phrases that begin to unravel the takenfor-granted melody that we all seem to be humming along to. What is important here is to focus on what it is we can do. I have no illusions that Eurovision education will be totally reformed by a few research projects; however, we can certainly take some responsibility in order not to worsen what is for many an already dire situation. It means attending to the actual lives of youth and their experiences by paying attention to the specific ways they 'exist' and 'become', as part of the 'everyday 
sublime'. Research with lives in transition not only provides an alternative to seeing transition as defined solely by the needs of economic exigencies, but it also responds with respect to the uncertainties bound up with individuals' experiences in the present. Facing uncertainty in our research builds not on adopting the lyrics of Eurovision education as our own but on listening to the voices of youth that are currently in the background in order to help them sing out - and sing loud.

\section{Declaration of conflicting interest}

The author(s) declared no potential conflicts of interest with respect to the research, authorship, and/or publication of this article.

\section{Funding}

The author(s) received no financial support for the research, authorship, and/or publication of this article.

\section{Notes}

1. Education and Training 2020 (ET 2020) is the EU 'framework for cooperation in education and training'. It provides '... a forum for exchanges of best practices, mutual learning, gathering and dissemination of information and evidence of what works, as well as advice and support for policy reforms'. See: http:// ec.europa.eu/education/policy/strategic-framework/index_en.htm (accessed 30 August 2016).

2. The Latin root is 'transire', from 'trans' (across) and 'ire' (go). See, for example, The Concise Oxford English Dictonary, 9th Edition (1995). Oxford: Oxford University Press.

3. See: https://ec.europa.eu/programmes/horizon2020/ (accessed 30 August 2016).

\section{References}

Arendt H (1983/1968) Between Past and Future. Eight Exercises in Political Thought. New York: Penguin. Batchelor S (2014) The everyday sublime. In: Bazzanno M (ed.) After Mindfulness: New Perspectives on Psychology and Meditation. New York: Palgrave Macmillan, pp. 37-48.

Biesta G (2010) Good Education in an Age of Measurement: Ethics, Politics, Democracy. Boulder, CO: Paradigm.

Colvin S (ed.) (1925 [1891]) Letters of John Keats to His Family and Friends (reprinted edition). London: Macmillan, p. 48. Available at: https://www.gutenberg.org/files/35698/35698-h/35698-h.htm\#Page 48 (accessed 30 August 2016).

European Commission (2015) New priorities for European cooperation in education and training. Joint Report of the Council and the Commission on the Implementation of the Strategic Framework for European Cooperation in Education and Training (ET2020). Brussels: European Commission.

Greene M (1988) The Dialectic of Freedom. New York: Teachers College Press.

Masschelein J (2011) Philosophy of education as an exercise in thought: To not forget oneself when 'things take their course'. European Educational Research Journal 10(3): 356-363.

Neave G (2003) On scholars, hippopotami and von Humboldt: Higher education in Europe in transition. Higher Education Policy 16(2): 135-140.

OECD (2013) Education Indicators in Focus. Paris: OECD Publications.

Todd S (2011) Becoming present in context: The politics of the gap in educational transformation. European Educational Research Journal, 10(3): 356-363.

Todd S (2015) Experiencing change, encountering the unknown: An education in 'negative capability' in light of Buddhism and Levinas. Journal of Philosophy of Education 49(2): 240-254.

\section{Author biography}

Sharon Todd, $\mathrm{PhD}$, is the head of department of Education at the Stockholm University in Sweden. Her research interests have been interdisciplinary in nature, and she brings into conversation the humanities-based traditions of scholarship with a social science commitment to concrete change and analysis. 